\title{
Correlates of Posttraumatic Stress Disorder in Forensic Psychiatric Outpatients in the Netherlands
}

\author{
Jens Henrichs ${ }^{1}$ and Stefan Bogaerts ${ }^{1,2}$ \\ ${ }^{1}$ International Victimology Institute, Tilburg University, Tilburg, The Netherlands \\ ${ }^{2}$ Department of Developmental, Clinical and Crosscultural Psychology, Tilburg University, Tilburg, The Netherlands
}

\begin{abstract}
Using a sample of 154 Dutch forensic psychiatric outpatients aged 18-62 years, this study investigated whether risk factors of posttraumatic stress disorder (PTSD), mainly identified in nonforensic research, forensic psychiatric factors, and potential comorbid mental disorders were associated with PTSD. Data on demographics, victimization during childhood or adolescence, and forensic psychiatric factors were derived from electronic medical records. Mental disorders were assessed using structured psychiatric interviews and consensus diagnoses were established during weekly case consultations. The PTSD rate was $75 \%$ in the sample. Whereas the PTSD group was significantly more likely to be older, female, not Dutch, and to have a history of victimization, previously perpetrated family violence, and lower psychosocial and occupational functioning than the non-PTSD group, the latter group had significantly higher rates of psychiatric history, attention-deficit/hyperactivity disorder (ADHD), antisocial personality disorder, drug abuse, and previous repeated nonfamily violence perpetration. Effect sizes ranged from Nagelkerke $R^{2}=.04$ for psychosocial and occupational functioning to Nagelkerke $R^{2}=.70$ for ADHD. This study demonstrated differences between those with and without PTSD in demographic, victim, forensic, and psychological characteristics. Future studies should examine the complexity between early victimization, delinquency patterns, and psychopathology regarding the prediction of PTSD among forensic psychiatric outpatients.
\end{abstract}

Posttraumatic stress disorder (PTSD) comprises a set of symptoms that may arise in individuals being exposed to or having witnessed life-threatening events, such as severe accidents, physical attacks, negative childhood experiences or interpersonal violence like rape (American Psychiatric Association [APA], 2000). Previous research indicates a much higher lifetime prevalence of PTSD among offender populations (ranging from $32 \%$ to $65 \%$ ) than in the general population (i.e., $6.8 \%$ in the United States and $7.4 \%$ in the Netherlands; de Vries, \& Olff, 2009; Gibson et al., 1999; Kessler, Berglund, et al., 2005; Papanastassiou, Waldron, Boule, \& Chesterman, 2004; Spitzer, Chevalier, Gillner, Freyberger, \& Barnow, 2006; Spitzer et al., 2001; Urbaniok, Endrass, Noll, Vetter, \& Rossegger, 2007). Estimates of the prevalence of current PTSD range from 17\%$36 \%$ among forensic populations (Gibson et al., 1999; Kristiansson, Sumelius, \& Sondergaard, 2004; Spitzer et al., 2001, 2006; Urbaniok et al., 2007). In a study in Switzerland of 86 adult offenders who were remand prisoners or receiving courtordered therapy as in- or outpatients, $75 \%$ of the sample had experienced at least one severe traumatic event and $27 \%$ had

Correspondence concerning this article should be addressed to Stefan Bogaerts, International Victimology Institute Tilburg, Tilburg University, P.O. Box 90 153, 5000 LE Tilburg, The Netherlands. E-mail: s.bogaerts@uvt.nl

Copyright (C) 2012 International Society for Traumatic Stress Studies. View this article online at wileyonlinelibrary.com

DOI: $10.1002 /$ jts. 21706 current PTSD (Urbaniok et al., 2007). Similarly, in a study of 32 adult forensic inpatients in Germany, $81 \%$ of the inpatients had experienced at least two types of child maltreatment, e.g., emotional, physical, or sexual abuse, but the 3-month prevalence of complex PTSD was only 28\% (Spitzer et al., 2006). This demonstrates that forensic psychiatric patients constitute a highly traumatized group and that, as in many other groups, some individuals are more vulnerable than others to developing PTSD after experiencing some type of trauma (Husain, Allwood, \& Bell, 2008).

This raises the question of identifying risk factors of PTSD. Prior to outlining the goals of the current study, which utilized a clinical sample of forensic psychiatric outpatients in the Netherlands, findings from other studies that have examined possible risk factors of PTSD are summarized. A meta-analysis by Ozer, Best, Lipsey, and Weiss (2003) based on community and clinical samples, but not forensic populations, identified seven empirically based risk factors for PTSD: peritraumatic dissociation, peritraumatic emotional responses, trauma severity, history of trauma/victimization, psychiatric history, family psychiatric history, and posttrauma social support. An earlier meta-analysis by Brewin, Andrews, and Valentine (2000) also identified most of these predictors, but also showed that some risk factors, including gender, education, low intelligence, and ethnicity were only significant in certain victim populations (military or civilian), but did not uniformly predict PTSD. 
Less is known, however, about risk factors for PTSD among forensic psychiatric in- or outpatients. Having a white-collar profession was associated with a lower risk of PTSD among offenders in Switzerland (Urbaniok et al., 2007). In a Swedish study of 25 Swedish and 25 immigrant offenders who underwent forensic psychiatric evaluation, PTSD was 5 times more common in the immigrant group (Kristiansson et al., 2004). In the same study, offenders with PTSD had a significantly larger proportion of both sexual and violent crimes and significantly lower psychosocial and occupational functioning than offenders without PTSD. Kristiansson et al. (2004) also found that the PTSD group was more likely to have been exposed to repeated and long-term traumatic events. Spitzer et al. (2006) reported significantly higher rates of exposure to childhood physical abuse among forensic psychiatric inpatients $(N=32)$ with complex PTSD than without complex PTSD. Additionally, mentally ill perpetrators of homicide $(N=19)$ were more likely to develop PTSD if the homicide victim was a family member (Papanastassiou et al., 2004). Finally, the study by Stuart, Moore, Gordon, Ramsey, and Kahler (2006) found that $44 \%$ of female perpetrators of domestic violence referred to court-mandated treatment $(N=103)$ reported symptoms of PTSD. This set of forensic studies suggests that demographic disadvantages, childhood victimization, repeated and long-term trauma, previous perpetration of sexual and (severe) violent crimes, and lower psychosocial and occupational functioning are risk factors of PTSD among this particular population.

Apart from the risk factors described above, several studies suggest that PTSD is associated with other psychiatric disorders. Research based on population-based samples and offender populations indicates comorbidity of PTSD with mood, anxiety, and substance abuse disorders in particular (Breslau, Davis, Peterson, \& Schultz, 1997; Gibson et al., 1999; Kessler, Chiu, Demler, Merikangas, \& Walters, 2005; Kristiansson et al., 2004; Ruchkin, Schwab-Stone, Koposov, Vermeiren, \& Steiner, 2002; Spitzer et al., 2001). Attention-deficit/hyperactivity disorder (ADHD) and antisocial personality disorder have also often been identified as comorbid disorders in diverse populations (e.g., juvenile delinquents or inmates; Adler, Kunz, Chua, Rotrosen, \& Resnick, 2004; Gibson et al. 1999; Husain et al., 2008; Ruchkin et al., 2002). Although part of the association between PTSD and other mental disorders may be artifactual due to the overlap of PTSD criteria with, for example, criteria for anxiety, somatoform, and affective syndromes, as well as ADHD symptomatology, at least two possible causal pathways have been suggested that might explain comorbidity between PTSD and other mental disorders (Breslau et al., 1997). Either mental illnesses increase the vulnerability for exposure to traumatic events and victimization and subsequent onset of PTSD, or mental illnesses occur after the onset of PTSD. Studying the comorbidity between PTSD and other mental disorders can have important clinical implications, as in this way mental disorders can be identified for which PTSD should be considered during differential diagnoses and treatment procedures.

Using data obtained from medical registries and structured clinical interviews in a sample of forensic psychiatric outpatients in the Netherlands, our study had three aims: (a) to explore whether a large number of risk factors of PTSD mainly identified in previous nonforensic research (i.e., demographic factors, history of different types of victimization, family history of psychiatric disorder, low intelligence, level of social support, and psychosocial and occupational functioning) were also related to PTSD; (b) to examine the comorbidity between PTSD and several other mental disorders; and (c) to examine whether numerous criminal justice factors, including legal status and various previous offenses, were associated with PTSD.

\section{Method}

\section{Participants}

The present study was based on a clinical sample of 154 forensic psychiatric outpatients treated by the forensic psychiatric policlinic "Het Dok" with treatment centers in Rotterdam, Breda, Dordrecht, and Tilburg, the Netherlands. This study was conducted in Rotterdam. Data collection and participant recruitment were conducted between January 2010 and February 2011. Written informed consent was obtained from all participants. The study has been approved by the Scientific Research Committee of the Forensic Psychiatric Center "De Kijvelanden" in Rotterdam, the Netherlands. Data were collected as part of routine outcome monitoring, are reported at group level, and cannot be traced back to the individual patient.

In total, some data were available for 201 outpatients, but 29 had to be excluded because they were younger than 18 years of age, and in 18 no data on PTSD were available. This left 154 participants $(89.5 \%)$ that were included in one or more of the analyses.

The current sample included $116(75.3 \%)$ forensic psychiatric outpatients with PTSD and $38(24.7 \%)$ without PTSD. Participants were aged 34.3 years $(S D=9.6)$ on average. As shown in Table 1, men (84.4\%) were strongly overrepresented in this sample. Almost half of the participants were non-Dutch (44.9\%). Of the included participants, 3.9\% received high education, $37.3 \%$ received medium education, and the majority (i.e., 58.8\%) of the sample had a low educational level. Almost $32 \%$ was married or cohabiting and the remaining participants had no romantic relationship. Additionally, $64.8 \%$ was voluntary outpatient. Of the outpatients, $25.6 \%$ were treated at the forensic policlinic under conditional regulations and $9.6 \%$ had a different legal status. Almost $90 \%$ had committed criminal offenses in the past.

To examine whether missing data on PTSD was selective, we compared core data of the outpatients included in this study with eligible outpatients without data on PTSD. Analysis of missing 
Table 1

Demographic and Forensic Characteristics by PTSD Status

\begin{tabular}{|c|c|c|c|c|c|c|c|}
\hline \multirow[b]{2}{*}{ Variable } & \multicolumn{2}{|c|}{$\begin{array}{c}\text { No PTSD } \\
(n=38)\end{array}$} & \multicolumn{2}{|c|}{$\begin{array}{c}\text { PTSD } \\
(n=116)\end{array}$} & \multicolumn{2}{|c|}{$\begin{array}{c}\text { Total } \\
(n=154)\end{array}$} & \multirow[b]{2}{*}{$p$} \\
\hline & $n$ & $\%$ & $n$ & $\%$ & $n$ & $\%$ & \\
\hline Gender & & & & & & & .001 \\
\hline Male & 38 & 20.7 & 92 & 79.3 & 130 & 84.4 & \\
\hline Female & 0 & 0.0 & 24 & 100.0 & 24 & 16.6 & \\
\hline Education & & & & & & & .733 \\
\hline Low & 16 & 64.0 & 44 & 57.1 & 60 & 58.8 & \\
\hline Medium & 9 & 36.0 & 29 & 37.7 & 38 & 37.3 & \\
\hline High & 0 & 0.0 & 4 & 5.2 & 4 & 3.9 & \\
\hline Ethnicity & & & & & & & $<.001$ \\
\hline Dutch & 33 & 86.8 & 48 & 44.0 & 81 & 55.1 & \\
\hline Non-Dutch & 5 & 13.2 & 61 & 56.0 & 66 & 44.9 & \\
\hline Marital status & & & & & & & .073 \\
\hline Married/cohabiting & 6 & 18.7 & 35 & 35.7 & 41 & 31.5 & \\
\hline Single/never married & 26 & 81.3 & 63 & 64.3 & 89 & 68.5 & \\
\hline Legal status & & & & & & & .519 \\
\hline Voluntary & 15 & 55.6 & 66 & 67.3 & 81 & 64.8 & \\
\hline Conditional & 8 & 29.6 & 22 & 22.4 & 30 & 25.6 & \\
\hline Other & 4 & 14.8 & 10 & 10.2 & 14 & 9.6 & \\
\hline \multicolumn{8}{|l|}{ Forensic history } \\
\hline Delinquency & 28 & 84.8 & 95 & 89.6 & 123 & 88.5 & .533 \\
\hline Serious property crimes & 4 & 14.8 & 17 & 18.5 & 21 & 17.6 & .780 \\
\hline Incidental nonfamily violence & 6 & 22.2 & 19 & 20.9 & 25 & 20.1 & 1.00 \\
\hline Repeated nonfamily violence & 15 & 55.6 & 31 & 34.1 & 46 & 39.0 & .044 \\
\hline Family violence & 2 & 7.4 & 30 & 33.0 & 32 & 27.1 & .009 \\
\hline Serious maltreatment & 7 & 25.9 & 22 & 23.9 & 29 & 24.4 & .804 \\
\hline Sexual abuse & 1 & 3.7 & 5 & 5.4 & 6 & 5.0 & 1.00 \\
\hline Attempted murder or manslaughter & 3 & 11.1 & 11 & 12.2 & 14 & 12.0 & 1.00 \\
\hline
\end{tabular}

Note. PTSD = posttraumatic stress disorder.

data showed no differences in age, marital status, education, legal status, history of delinquency, and psychosocial and occupational functioning. Outpatients included in this study, however, were more likely to be non-Dutch compared to excluded outpatients, $44.9 \%$ versus $11.1 \%, \chi^{2}(1, N=197)=7.56, p=$ .005 .

\section{Measures}

All data were retrieved from electronic patient records, a digital medical registry system used to obtain and store patient information in the Netherlands. Data on demographic factors included information on age, gender, ethnicity, educational level, and marital status. Following the definitions of Statistics Netherlands (2004), we divided education into low (no education, primary school or $\leq 3$ years secondary school), medium ( $>3$ years secondary school, intermediate vocational training), and high (higher vocational training, university degree).
Outpatients were assessed for PTSD and other concurrent mental disorders by a senior psychiatrist and a psychologist trained in conducting structured psychiatric interviews (Groenestijn, van Akkerhuis, Schneider, Kupka, \& Nolen, 1999; Weertman, Arntz, \& Kerkhofs, 2000) based on the guidelines of the Diagnostic and Statistical Manual of Mental Disorders (4th ed.; DSM-IV; APA, 2000). A consensus diagnosis for each patient in the sample was established during weekly case consultations. Psychosocial and occupational functioning was assessed by a psychologist using the Dutch translation of the Global Assessment of Functioning (GAF) scale (APA, 2001). Information on drug abuse, psychiatric family history, psychiatric history in adolescence and/or childhood, and history of different types of victimization during childhood or adolescence (i.e., psychological, physical, and sexual victimization) was obtained from several different interviews. Data on legal status and history of delinquency, including information on the nature of diverse previous offenses, was retrieved from the $\mathrm{Na}-$ tional Dutch resocialization agency (Reclassering Nederland). 
Table 2

Victim History, Comorbidity, and other Risk Factors by PTSD Status

\begin{tabular}{|c|c|c|c|c|c|c|c|}
\hline \multirow[b]{2}{*}{ Variable } & \multicolumn{2}{|c|}{$\begin{array}{c}\text { No PTSD } \\
(n=38)\end{array}$} & \multicolumn{2}{|c|}{$\begin{array}{c}\text { PTSD } \\
(n=116)\end{array}$} & \multicolumn{2}{|c|}{$\begin{array}{c}\text { Total } \\
(n=154)\end{array}$} & \multirow[b]{2}{*}{$p$} \\
\hline & $n$ & $\%$ & $n$ & $\%$ & $n$ & $\%$ & \\
\hline Psychological victimization & 10 & 71.4 & 65 & 89.0 & 75 & 86.2 & .097 \\
\hline Physical victimization & 9 & 60.0 & 73 & 89.0 & 82 & 84.5 & .011 \\
\hline Sexual victimization & 1 & 7.7 & 34 & 47.2 & 35 & 41.2 & .008 \\
\hline Sexual/physical victimization & 6 & 66.7 & 63 & 92.6 & 69 & 89.6 & .047 \\
\hline Any form of victimization & 14 & 66.7 & 81 & 89.0 & 95 & 84.8 & .017 \\
\hline Psychiatric history & 28 & 100.0 & 58 & 75.3 & 86 & 81.9 & .003 \\
\hline Psychiatric family history & 8 & 36.4 & 34 & 46.6 & 42 & 44.2 & .398 \\
\hline Lack of social support & 6 & 20.0 & 19 & 22.1 & 25 & 21.6 & .810 \\
\hline Low intelligence & 2 & 5.3 & 6 & 5.3 & 8 & 5.3 & 1.00 \\
\hline Anxiety disorder & 0 & 0.0 & 7 & 6.5 & 7 & 4.9 & .194 \\
\hline Mood disorder & 8 & 21.1 & 42 & 38.5 & 50 & 34.0 & .050 \\
\hline ADHD & 36 & 94.7 & 12 & 12.1 & 48 & 35.0 & $<.001$ \\
\hline Antisocial personality disorder & 13 & 68.4 & 23 & 34.8 & 36 & 42.4 & .009 \\
\hline Drug abuse & 28 & 80.0 & 61 & 58.7 & 89 & 64.0 & .023 \\
\hline Addiction & 23 & 65.7 & 55 & 50.0 & 78 & 53.8 & .104 \\
\hline
\end{tabular}

Note PTSD $=$ posttraumatic stress disorder; $\mathrm{ADHD}=$ attention-deficit/hyperactivity disorder.

\section{Data Analysis}

Outpatients with and without PTSD were compared on all variables and concurrent mental disorders using independent $t$ tests for continuous variables. As recommended by Field (2009), for comparisons based on categorical variables, chi-square tests or Fisher's exact tests were used in the case of empty cells or expected cell counts below 5 in more than $20 \%$ of the cells. To address the main aims of this study, correlates that significantly differentiated between outpatients with and without PTSD were then used in univariate logistic regression analyses to illustrate the direction and magnitude of the associations of these variables with PTSD. To illustrate the magnitude of these associations Nagelkerke $R^{2}$ was reported. In line with the recommendations by Field, only categorical variables without empty cells or expected cell counts $>5$ (i.e., categorical variables meeting the chi-square test assumptions) were included in the univariate logistic regression analyses. All analyses were complete case analyses.

\section{Results}

\section{Characteristics Associated With PTSD}

The PTSD group was older $(M=35.4, S D=9.9)$ than the non-PTSD group $(M=30.7, S D=7.9), t(152)=2.67, p=$ .008. Table 1 presents demographic and forensic factors as a function of PTSD. In comparison to men, women were more likely to have PTSD and the PTSD group was more likely to be non-Dutch. Additionally, forensic psychiatric outpatients with PTSD were more likely to have committed previous family violence offenses, but less likely to have a history of repeated non-family violence offenses than outpatients without PTSD. The remaining demographic and criminological characteristics did not significantly differ between the PTSD and non-PTSD group.

Table 2 shows psychopathological characteristics of the current sample. Approximately $75 \%$ of the participating forensic psychiatric outpatients had PTSD. In $4.9 \%$ of the forensic psychiatric outpatients, an anxiety disorder other than PTSD was diagnosed. Moreover, 34\% had a mood disorder and 35\% suffered from ADHD. Additionally, $42.4 \%$ of the sample had an antisocial personality disorder. In addition, 64\% abused drugs and $53.8 \%$ were addicted. Finally, participants had an average score of $49.8(S D=9.4)$ on the GAF scale assessing psychosocial and occupational functioning in adulthood.

Table 2 also shows the status of the PTSD and non-PTSD group concerning victimological and psychopathological characteristics. The two groups differed in all types of previous victimization except for history of psychological victimization. Forensic psychiatric outpatients with PTSD were more likely to have been victims of sexual violence, physical violence, both sexual and physical violence and to have been victims of any form of previous victimization (defined as a history of psychological, physical, and/or sexual victimization). For example, whereas $66.7 \%$ of the outpatients without PTSD had experienced any form of victimization during childhood or adolescence, $89.0 \%$ of the PTSD group had been exposed to at least one type of victimization. The PTSD group was more likely to display lower mean GAF scores $(M=49.8, S D=7.8$ vs. $M=52.5, S D=13.1), t(141)=1.98, p=.049$, but less likely 
Table 3

Summary of 9 Univariate Logistic Regression Analyses Showing Odds of PTSD

PTSD

\begin{tabular}{lrrrc}
\cline { 3 - 4 } Variable $^{\mathrm{a}}$ & $n$ & OR & $95 \% \mathrm{CI}$ & \multicolumn{2}{c}{ Nagelkerke $R^{2}$} \\
\hline Years of age & 154 & 1.06 & {$[1.01,1.10]$} & $.07^{*}$ \\
Non-Dutch ethnicity & 147 & 8.39 & {$[3.04,23.12]$} & $.21^{* * *}$ \\
Repeated nonfamily violence & 118 & 0.41 & {$[0.17,0.99]$} & $.05^{*}$ \\
Previous family violence & 118 & 6.15 & {$[1.37,27.69]$} & $.10^{*}$ \\
History of sexual victimization & 85 & 10.74 & {$[1.33,86.96]$} & $.17^{*}$ \\
GAF & 143 & 0.96 & {$[0.92,1.00]$} & $.04^{*}$ \\
ADHD & 137 & 0.01 & {$[0.00,0.04]$} & $.70^{* * *}$ \\
Antisocial personality disorder & 85 & 0.25 & {$[0.08,0.74]$} & $.12^{*}$ \\
Drug abuse & 139 & 0.26 & {$[0.14,0.87]$} & $.06^{*}$ \\
\hline
\end{tabular}

Note. $\mathrm{PTSD}=$ posttraumatic stress disorder; $\mathrm{GAF}=$ Global Assessment of Functioning; $\mathrm{ADHD}=$ attention-deficit/hyperactivity disorder.

${ }^{\text {a } I n}$ all cases the reference group (not shown) is the absence of the characteristic of the independent variable.

${ }^{*} p<.05 .{ }^{* *} p<.01 .{ }^{* * *} p<.001$.

to have a history of psychiatric disorders in adolescence and/or childhood, ADHD, and antisocial personality disorder than the non-PTSD group. Finally, drug abuse was less common among the PTSD group. There were no significant differences on the remaining characteristics.

\section{Correlates of PTSD}

The results of the univariate logistic regression analyses are presented in Table 3. Being older was significantly, but rather weakly related to a higher risk of PTSD. Being non-Dutch was associated with an approximately 8 times higher risk of PTSD and explained a moderate amount of variance in PTSD. Previous family violence offending was related to an approximately 6 times higher risk of PTSD, but it explained a small-to-moderate amount of the variance of PTSD. Although history of sexual victimization was linked to an almost 11 times higher risk of PTSD, it only accounted for a moderate amount of variance. Interestingly, previous repeated nonfamily violence offending, higher psychosocial and occupational functioning, ADHD, antisocial personality disorder, and drug abuse were all related to a lower risk of PTSD. All these factors were significantly, but weakly associated with a lower risk of PTSD with one exception: The size of the negative association between ADHD and PTSD was strong. In a univariate logistic regression, ADHD was related to a 99\% lower risk of PTSD and explained a large amount of variance.

\section{Discussion}

This study revealed important demographic differences and differences in history of victimization, types of previous offenses, psychosocial and occupational functioning, and concurrent mental disorders between forensic psychiatric outpatients with and without PTSD. In line with previous research (Briere
\& Runtz, 1993; Gibson et al., 1999; Ozer et al., 2003; Spitzer et al., 2001, 2006) the present study demonstrated significantly higher rates of early experiences of sexual and physical victimization among forensic psychiatric outpatients with PTSD. This suggests that a history of early victimization increases the vulnerability to develop PTSD in adulthood. Previous research suggests that cognitive maintaining factors and distortions, such as mental defeat, rumination about trauma, negative appraisal of the self, and self-perceptions of helplessness and chronic danger might partly explain why some traumatized people develop persistent PTSD whereas others recover on their own (Briere \& Runtz, 1993; Kleim, Ehlers, \& Glucksman, 2007). It would be interesting to address whether these cognitive maintaining factors and distortions may also partly account for the association between early experiences of victimization and PTSD in the forensic psychiatric population.

This study showed that previous family violence perpetration was associated with a higher risk of PTSD consistent with the study by Stuart et al. (2006). This finding can be interpreted in several ways. First, the perpetration of family violence itself may be traumatic. Previous research indeed suggests that offenders are more likely to experience symptoms of PTSD if they have been emotionally attached to the victim (Papanastassiou et al., 2004). Second, due to the cross-sectional study design we cannot rule out that the forensic psychiatric outpatients already suffered from PTSD when perpetrating family violence as previous research suggests that PTSD may be related to an increased risk of engaging in subsequent violent acts (Goldenson, Spidel, Greaves, \& Dutton, 2009). Third, when taking into account that a large amount of the PTSD group had been exposed to early sexual and physical victimization, one might speculate that these experiences can lead to both family violence perpetration and PTSD as previous research observed longterm associations of early experiences of victimization with both of these adverse outcomes (Briere \& Runtz, 1993; Murrel, 
Christoff, \& Henning, 2007). It is not clear, however, whether PTSD mediates the association between early experiences of victimization and family violence perpetration or whether victims of violence in childhood or adolescence who turn into perpetrators of family violence, possibly due to observational learning of violence in their family of origin (Grych \& Fincham, 1990), are also more prone to develop PTSD as a consequence of their violent acts. Therefore, future longitudinal studies are needed to shed more light on the interconnectedness between these factors. Most important, the current findings suggest that an acknowledgment of trauma precursors to family violence perpetration should be integrated into treatment protocols.

Unexpectedly, this study demonstrated an inverse and strong association between ADHD and PTSD, although previous research suggests that ADHD increases the vulnerability for developing PTSD (Adler et al., 2004; Husain et al., 2008; Ruchkin et al., 2002). In numerical terms, this finding reflects the observed proportions of forensic psychiatric outpatients with ADHD in the PTSD group and non-PTSD group (i.e., almost every forensic outpatient without PTSD had ADHD (95\%), whereas only a small group of the outpatients with PTSD was diagnosed with ADHD (12\%). The reason for the observed inverse association between ADHD and PTSD is not known and this could just be a chance finding. Strikingly, in contrast to previous research based on offender populations (Gibson et al., 1999; Kristiansson et al. 2004; Spitzer et al., 2006), the current study, however, also showed that previous perpetration of repeated nonfamily violence, antisocial personality disorder, and drug abuse were inversely related to PTSD. Although this pattern of results seems counterintuitive, one should bear in mind that rates of these factors were relatively high in both the PTSD group and the non-PTSD group. For example, almost $60 \%$ of the PTSD group displayed drug abuse, but in the non-PTSD group the drug abuse rate was even higher (i.e., $80 \%$ ). This very high rate of drug abuse in the non-PTSD group might be due to the fact that almost each outpatient in the non-PTSD group also had ADHD. In line with the self-medication hypothesis PTSD and ADHD have been shown to be related to drug abuse (Chilcoat \& Breslau, 1998; Wilens et al., 2007). However, the National Comorbidity Survey Replication in the United States $(n=3,199)$ reported stronger associations between ADHD and drug abuse than between PTSD and drug abuse (Kessler et al., 2005).

In general, one might speculate that the observed differences in rates of ADHD, antisocial personality disorder, drug abuse, and types of previous offenses in both groups suggest different typological characteristics of forensic psychiatric outpatients with and without PTSD. It is particularly tempting to do this when also considering that the PTSD group was less likely to have a psychiatric history in childhood and/or adolescence than the non-PTSD group consistent with the study by Papanastassiou et al. (2004). Notably, in the non-PTSD group almost each forensic psychiatric outpatients suffered from ADHD, an early onset psychiatric disorder, all outpatients had a psychiatric history, and the majority of this group had an antisocial personality disorder. Thus, the non-PTSD group possibly concerns mentally ill offenders that probably already developed delinquent behavior patterns early in life due to their childhood (neuro-) psychiatric problems in line with the theory of life-course-persistent antisocial behavior (Moffit, 1993). Moreover, it seems likely that the non-PTSD group was more often engaged in previous nonfamily violent offenses probably due to its high rates of ADHD-related impulsivity, antisocial personality traits, and drug abuse, which is known to reduce self-control and judgement and to increase levels of aggression. The group of forensic psychiatric outpatients with PTSD, on the other hand, seems to concern a group of less antisocial mentally ill offenders that are highly traumatized. This latter group seems to be more likely to perpetrate family violence because of their potential observational learning history of family violence early in life, possibly induced by their early experiences of victimization (Grych \& Fincham, 1990). However, one should be cautious to generalize the current findings to other (nonforensic) populations due to the small sample size of this cross-sectional study and specific characterics of forensic psychiatric outpatients. Longitudinal forensic research based on larger study samples is needed to confirm the pattern of results observed in the current study regarding the association of ADHD, antisocial personality disorder, and drug abuse with PTSD in this particular population.

In line with previous research based on general population, clinical and forensic samples being female, having a minority status (i.e., being non-Dutch), being older, and lower psychosocial and occupational functioning was more common among the PTSD group (Brewin et al., 2000; Kristiansson, 2004). Moreover, the PTSD group more often experienced sexual and physical victimization early in life. This suggests that more vulnerable, less well psychosocially functioning, demographically disadvantaged, and highly traumatized individuals are more likely to develop PTSD. A possible mental health implication is to develop specific trauma-reduction-oriented treatment modules and intervention programs that take these earlier described characteristics of forensic psychiatric outpatients with PTSD into account.

Although this study identified several demographic, victimological, criminological, and psychopathological correlates of PTSD among forensic psychiatric outpatients, other factors might also be related to PTSD. One such factor might be a certain genetic makeup. A multigenerational family study by Goenjian et al. (2008) indicated substantial genetic liability for PTSD, suggesting that several susceptibility genes might make some individuals more vulnerable than others to develop PTSD. Another factor might be specific brain laterality, as patients with PTSD have displayed distinct patterns of resting electroencephalogram-alpha asymmetry in comparison to patients with a major depressive disorder and controls (Kemp et al., 2010).

Several potential limitations of the study must be discussed. First, it is difficult to generalize our findings to other clinical populations as this study was based on a sample of forensic 
psychiatric outpatients. Second, although the rate of PTSD was relatively high in this study, statistical power was low to detect small effect sizes due to the small sample size. Moreover, due to the small sample size and large amount of missing values in some variables, this study did not allow identifying independent risk factors of PTSD using a multivariate logistic regression model. Third, data on history of victimization, psychiatric (family) history, and drug abuse was reported retrospectively. This information could therefore be distorted due to recall bias. A prospective longitudinal design could prevent this shortcoming. Fourth, it would have been advantageous if data on interrater reliability of the structured psychiatric interviews had been available. Nevertheless, consensus diagnoses were based on clinical judgments of trained clinicians. Finally, missing data analyses revealed that forensic psychiatric outpatients without data on PTSD were more likely to be non-Dutch than included outpatients. Therefore, missing data could have led to an underestimation of the association of the different correlates with PTSD, but probably not to spurious associations.

In conclusion, the findings of this study provided insights in correlates of PTSD among forensic psychiatric outpatients that might be helpful for the development of specific treatment and intervention programs addressing the reduction of PTSD among the forensic population. Moreover, this study revealed important demographic, victimological, criminological, and psychopathological differences between the PTSD and nonPTSD group, suggesting specific typological characteristics for these two groups of forensic psychiatric outpatients. Future longitudinal large-scale studies should investigate the complexity between early experiences of victimization, patterns of delinquency, and psychopathology with regard to the prediction of PTSD taking into account neuropsychiatric, genetic, psychological, and cognitive factors.

\section{References}

Adler, L. A., Kunz, M., Chua, H. C., Rotrosen, J., \& Resnick, S. G. (2004). Attention-deficit/hyperactivity disorder in adult patients with posttraumatic stress disorder (PTSD): Is ADHD a vulnerability factor? Journal of Attention Disorders, 8, 11-16. doi:10.1177/108705470400800102

American Psychiatric Association. (2000). Diagnostic and statistical manual of the mental disorders (4th ed., text rev.). Washington, DC: Author.

American Psychiatric Association. (2001). Beknopte handleiding bij de Diagnostische Criteria van de DSM-IV-TR [Dutch manual of the DSM-IV-TR diagnostic criteria] (pp. 76-77). Lisse, The Netherlands: Swets \& Zeitlinger.

Breslau, N., Davis, G. C., Peterson, E. L., \& Schultz, L. (1997). Psychiatric sequelae of posttraumatic stress disorder in women. Archives of General Psychiatry, 54, 81-87. doi:10.1001/archpsyc.1997.01830130087016

Brewin, C. R., Andrews, B., \& Valentine, J. D. (2000). Meta-analysis of risk factors for posttraumatic stress disorder in trauma-exposed adults. Journal of Consulting and Clinical Psychology, 68, 748-766. doi:10.1037/0022006X.68.5.748

Briere, J., \& Runtz, M. (1993). Childhood sexual abuse-long-term sequelae and implications for psychological assessment. Journal of Interpersonal Violence, 8, 312-330. doi:10.1177/088626093008003002

Chilcoat, H. D., \& Breslau, N. (1998). Investigations of causal pathways between PTSD and drug use disorders. Addictive Behaviors, 23, 827-840. doi:10.1016/S0306-4603(98)00069-0 de Vries, G. J., \& Olff, M. (2009). The lifetime prevalence of traumatic events and posttraumatic stress disorder in the Netherlands. Journal of Traumatic Stress, 22, 259-267. doi:10.1002/jts.20429

Field, A. (2009). Discovering statistics using SPSS (3rd ed.). Thousand Oaks, CA: Sage.

Gibson, L. E., Holt, J. C., Fondacaro, K. M., Tang, T. S., Powell, T. A., \& Turbitt, E. L. (1999). An examination of antecedent traumas and psychiatric comorbidity among male inmates with PTSD. Journal of Traumatic Stress, 12, 473-484. doi:10.1023/A:1024767020280

Goenjian, A. K., Noble, E. P., Walling, D. P., Goenjian, H. A., Karayan, I. S., Ritchie, T., \& Bailey, J. N. (2008). Heritabilities of symptoms of posttraumatic stress disorder, anxiety, and depression in earthquake exposed Armenian families. Psychiatric Genetics, 18, 261-266. doi:10.1097/YPG.0b013e3283060f48

Goldenson, J., Spidel, A., Greaves, C., \& Dutton, D. (2009). Female perpetrators of intimate partner violence: Within-group heterogeneity, related psychopathology, and review of current treatment with recommendations for the future. Journal of Aggression, Maltreatment \& Trauma, 18, 752-769. doi:10.1080/10926770903231791

Groenestijn, M. A. C., van Akkerhuis, G. W., Schneider, N., Kupka, R. W., \& Nolen, W. A. (1999). Gestructureerd Klinisch Interview voor de vaststelling van DSM-IV As I Stoornissen (SCID-I) [Structured Clinical Interview for DSM-IV Axis I Disorders (SCID-I)]. Amsterdam, The Netherlands: Pearson.

Grych, J. H., \& Fincham, F. D. (1990). Marital conflict and children's adjustment: A cognitive-contextual framework. Psychological Bulletin, 108, 267-290. doi:10.1037//0033-2909.108.2.267

Husain, S. A., Allwood, M. A., \& Bell, D. J. (2008). The relationship between PTSD symptoms and attention problems in children exposed to the Bosnian war. Journal of Emotional and Behavioral Disorders, 16, 52-62. doi:10.1177/1063426607310847

Kemp, A. H., Griffiths, K., Felmingham, K. L., Shankman, S. A., Drinkenburg, W., Arns, M., Bryant, R. A. (2010). Disorder specificity despite comorbidity: Resting EEG alpha asymmetry in major depressive disorder and post-traumatic stress disorder. Biological Psychology, 85, 350-354. doi:10.1016/j.biopsycho.2010.08.001

Kessler, R. C., Berglund, P., Demler, O., Jin, R., Merikangas, K. R., \& Walters, E. E. (2005). Lifetime prevalence and age-of-onset distributions of DSM-IV disorders in the National Comorbidity Survey Replication. Archives of General Psychiatry, 62, 593-602. doi:10.1001/archpsyc.62.6 .593

Kessler, R. C., Chiu, W. T., Demler, O., Merikangas, K. R., \& Walters, E. E. (2005). Prevalence, severity, and comorbidity of 12-month DSM-IV disorders in the National Comorbidity Survey Replication. Archives of General Psychiatry, 62, 617-627. doi:10.1001/archpsyc.62.6.617

Kleim, B., Ehlers, A., \& Glucksman, E. (2007). Early predictors of chronic postraumatic stress disorder in assault survivors. Psychological Medicine, 37, 1457-1467. doi:10.1017/S0033291707001006

Kristiansson, M., Sumelius, K., \& Sondergaard H. P. (2004). Post-traumatic stress disorder in the forensic psychiatric setting. Journal of the American Academy of Psychiatry and the Law, 32, 399-407.

Moffitt, T. E. (1993). Adolescence-limited and life-course-persistent antisocial behavior: A developmental taxonomy. Psychological Review, 100, 674701. doi:10.1037/0033-295X.100.4.674

Murrell, A. R., Christoff, K. A., \& Henning, K. R. (2007). Characteristics of domestic violence offenders: Associations with childhood exposure to violence. Journal of Family Violence, 22, 523-532. doi:10.1007/s10896007-9100-4

Ozer, E. J., Best, S. R., Lipsey, T. L., \& Weiss, D. S. (2003). Predictors of posttraumatic stress disorder and symptoms in adults: A metaanalysis. Psychological Bulletin, 129, 52-73. doi:10.1037//0033-2909.129 .1 .52

Papanastassiou, M., Waldron, G., Boyle, J., \& Chesterman, L. P. (2004). Post-traumatic stress disorder in mentally ill perpetrators of homicide. Journal of Forensic Psychiatry \& Psychology, 15, 66-75. doi:10.1080/14789940310001630419

Ruchkin, V. V., Schwab-Stone, M., Koposov, R., Vermeiren, R., \& Steiner, H. (2002). Violence exposure, posttraumatic stress, and personality in juvenile delinquents. Journal of the American Academy of Child \& Adolescent Psychiatry, 41, 322-329. doi:10.1097/00004583-20020300000012 
Spitzer, C., Chevalier, C., Gillner, M., Freyberger, H. J., \& Barnow, S. (2006). Complex posttraumatic stress disorder and child maltreatment in forensic inpatients. Journal of Forensic Psychiatry \& Psychology, 17, 204-216. doi:10.1080/14789940500497743

Spitzer, C., Dudeck, M., Liss, H., Orlob, S., Gillner, M., \& Freyberger, H. J. (2001). Post-traumatic stress disorder in forensic inpatients. Journal of Forensic Psychiatry, 12, 63-77. doi:10.1080/09585180121757

Statistics Netherlands. (2004). Standaard Onderwijsindeling 2003 [Categorization of the Dutch educational system 2003]. Voorburg/Heerlen, The Netherlands: Author.

Stuart, G. L., Moore, T. M., Gordon, K. C., Ramsey, S. E., \& Kahler, C. W. (2006). Psychopathology in women arrested for domestic violence. Journal of Interpersonal Violence, 21, 376-389. doi:10.1177/0886260505282888
Urbaniok, F., Endrass, J., Noll, T., Vetter, S., \& Rossegger, A. (2007). Posttraumatic stress disorder in a Swiss offender population. Swiss Medical Weekly, 137, 151-156.

Weertman, A., Arntz, A., \& Kerkhofs, M. L. M. (2000). Gestructureerd Klinisch Interview voor DSM-IV As-II Persoonlijkheidsstoornissen (SCID-II) [Structured Clinical Interview for DSMIV Axis II Disorders (SCID-II)]. Amsterdam, The Netherlands: Pearson.

Wilens, T. E., Adamson, J., Sgambati, S., Whitley, J., Santry, A., Monuteaux, M. C., \& Biederman, J. (2007). Do individuals with ADHD selfmedicate with cigarettes and substances of abuse? Results from a controlled family study of ADHD. American Journal of Addiction, 16, 14-23. doi:10.1080/10550490601082742 